\title{
Using a Physical Activity Application to Promote Physical Activity Levels Among Aged People: A Follow-Up Study
}

\author{
Tuomas Kari \\ ${ }^{1}$ Institute for Advanced Management \\ Systems Research, Turku, Finland \\ ${ }^{2}$ University of Jyvaskyla, Jyvaskyla, \\ Finland \\ tuomas.t.kari@jyu.fi \\ Lauri Frank \\ University of Jyvaskyla, Faculty of \\ Information Technology, Jyvaskyla, \\ Finland \\ lauri.frank@jyu.fi
}

\author{
Markus Makkonen \\ ${ }^{1}$ Institute for Advanced Management \\ Systems Research, Turku, Finland \\ ${ }^{2}$ University of Jyvaskyla, Jyvaskyla, \\ Finland \\ $\underline{\text { markus.makkonen@j.jyu.fi }}$
}

\author{
Joanna Carlsson \\ University of Turku, Faculty of \\ Science and Engineering, Turku, \\ Finland \\ joanna.p.carlsson@utu.fi
}

\begin{abstract}
The share and life expectancy of the ageing population are increasing. However, aged people are threatened by insufficient physical activity. Therefore, finding ways to support people to live a physically active life in older age is imperative. Digital wellness technologies represent a potential solution, but in order for such technologies to be effective, research is needed to gain a better understanding on their use among aged people. To address this need, this study investigated whether the use of a physical activity application can promote physical activity among aged people. The physical activity levels were measured at three different time points: before taking the application into use, after four months of use, and after 12 months of use. The results show a modest increase in the physical activity levels. When examining physical activity categories (based on the IPAQ-E), a participant rather shifted to a higher than to a lower physical activity category. Overall, the changes were more substantial after 12 months than after four months of use. The results suggest that physical activity applications used in everyday life have potential in promoting physical activity levels among aged people.
\end{abstract}

\section{Introduction}

Ageing people have become an increasing priority area for policy makers and healthcare providers globally. The global population aged 65 years or over is increasing rapidly and is predicted to double to 1.5 billion people by the year 2050 [1]. The percentage of people 65 years or over is the largest in Europe and Northern America, but their share is increasing worldwide [1]. For example, in Europe, where their share is the largest, persons aged 65 years or over already represent around 18-22\% of the population in most EU countries [2]. At the same time, the life expectancy at older ages is improving. Globally, a person aged 65 years was expected to live additional 17 years in 2015-2020, and this is expected to increase to additional 19 years by 2045-2050 [1]. As the global population is aging and the life expectancy is improving, it is imperative to find solutions that would support people to live a physically active life in older age in order to maintain their health and wellness as well as their ability to function.

This is a vital matter as physical activity (PA) has significant health benefits and contributes to the prevention of non-communicable diseases across all age groups [3]. PA also aids in upkeeping the ability to function when a person gets older, and it is imperative to ward off frailty and age-related illness [4]. Furthermore, several studies indicate that systematically conducted PA contributes to a better quality of life in older age [e.g., 5].

The World Health Organization (WHO) as well as several national health institutes provide researchbased PA guidelines and recommendations. For example, the guidelines by the WHO [3] state that adults aged 65 years or over should do at least 150 
minutes of moderate-intensity PA or at least 75 minutes of vigorous-intensity PA per week, or an equivalent combination of these. To reach additional health benefits, they should increase moderateintensity PA to 300 minutes per week (or equivalent). Furthermore, PA to enhance balance and musclestrength as well as to prevent falls should also be conducted.

Despite all the numerous global and national recommendations and guidelines for $\mathrm{PA}$, insufficient PA is a major global problem across all age groups and one of the leading risk factors for non-communicable diseases and death worldwide [3]. During the past year, this pandemic of insufficient PA has likely been further aggravated by another pandemic, the coronavirus disease 2019 (COVID-19) caused by the severe acute respiratory syndrome coronavirus 2 (SARS-CoV-2), which has limited the possibilities to conduct certain physical activities especially among the aged population. Therefore, new and innovative solutions to promote PA among aged people are urgently needed.

Researchers across various fields have taken serious efforts to find solutions to support PA behavior and tackle the prevalent issue of insufficient PA. Digital wellness technologies, which we define as digital technologies that can be used to support different aspects of wellness, represent a potential solution. These technologies include, for example, devices, applications, and services. Their potential to promote PA behaviors among aged people has been suggested, but questions have been placed regarding their effectiveness, and more research is warranted to gain insights on how such technologies are used, what is the outcome of their use, and how the use and the effects of use are perceived [6-8]. Researching this is importantly needed also in order to advance the design and development of digital wellness technologies aimed for aged people, as they are a user group with distinct needs and challenges.

To address the aforementioned research need, the main purpose of this study was to investigate the following research question: Does the use of a physical activity application promote physical activity levels among aged people?

The present study is part of a research program, in which groups of aged people take into use a physical activity application, that is, a mobile application for tracking, following, and supporting their everyday PA. The self-reported PA was measured by using the International Physical Activity Questionnaire modified for the elderly (IPAQ-E) [9] at three different time points: before taking the application into use, after four months of use, and after 12 months of use.

Ultimately, this study aims to contribute to the knowledge on how different digital wellness technologies could be better utilized to support PA behavior among aged people. At the same time the study contributes to the IS research stream of information technology's ability to persuade behavior change.

\section{Background}

\subsection{Digital wellness technology use among aged people}

The variety of different digital wellness technologies is enormous. There is a large selection of devices, applications, and services, which are aimed for specific or more general target groups. The use of such technologies has become increasingly common, and they are used by various types of users with different PA levels [10-11]. Despite the growth of their popularity in different user groups, typically these technologies are designed for younger people, although a growing need for such technologies is prevalent also among aged people $[6,12]$.

In general, digital wellness technologies can support PA in manifold ways. For example, they can be used to promote PA levels [e.g., 7, 13-14], and to decrease the time spent in sedentary behaviors [e.g., 15]. They can provide instructions for PA, and some sophisticated products also include digital coaching features [e.g., 16-18]. They can support goal-setting [e.g., 19-20] and include social features to provide social support [e.g., 21]. Many solutions also include gamified features [22-23] that aim to make PA more compelling and to increase the adherence of use and PA behavior. Exergames [e.g., 24-27] are games that combine PA with digital gaming. Digital wellness technologies can provide feedback regarding the user's actions in many ways. This feedback can increase the user's awareness of personal wellness and PA, and also act as a motivator towards improving related behavior [e.g., 28-30]. However, increased awareness might not be sufficient for the continued use of the technology [29, 31], and such "learning-effect" can even be a reason for use discontinuance [29 p. 285]. This, in turn, can disturb the adherence to PA routines [32-33].

Digital wellness technologies have been found promising in terms of promoting PA behavior and other aspects of wellness also among aged people [e.g., 7, 34-37]. For example, in studies focusing on aged people, Larsen et al. [7] found low quality evidence for a moderate effect of physical activity monitor-based interventions on PA. Changizi and Kaveh [34] found that mobile health solutions may improve, among other things, self-management, self-efficacy, and PA. Muellmann et al. [35] found that interventions utilizing 
eHealth solutions can effectively promote PA, at least on short-term. Similarly, Yerrakalva et al. [36] found that mobile health application-based interventions have the potential to promote PA and changes in sedentary time on short term. Stockwell et al. [37] found that digital behavior change interventions may increase PA and physical functioning as well as reduce sedentary time. Although the research on digital wellness technology use among aged people has been increasing, more high-quality and long-term studies are called for [e.g., 6, 12, 34-37].

\subsection{Information systems and behavior change}

One of the central reasons for using digital wellness technologies and physical activity applications is the expected positive effects on health and wellness behavior. As users engage with digital wellness technologies, they are receptive to potential changes in their PA behavior. Indeed, "information technology always influences people's attitudes and behaviors in one way or another" [57 p. 1225], while this influence can be intended or unintended [57].

As Oinas-Kukkonen [57] points out, there is a plethora of information systems that can be developed to persuade (either positive or negative) behavior changes. Such systems have been widely discussed in the literature using the terms persuasive technology [e.g., 58] or persuasive systems [e.g., 59]. In [57], Oinas-Kukkonen presented the concept of behavior change support system (BCSS), defined as "a sociotechnical information system with psychological and behavioral outcomes designed to form, alter or reinforce attitudes, behaviors or an act of complying without using coercion or deception". Thus, BCSSs emphasize the voluntariness of behavior change, and an ideal BCSS persuades the user to change behavior voluntarily [57]. BCSSs are, in essence, persuasive system. However, they place more emphasis on the actual outcome than a persuasive system [57]. The changes can be categorized into a change in an act of complying (C-change), a behavior change (B-change), and an attitude change (A-change) [57]. Whereas with $\mathrm{C}$-change the goal is simply to make the end-user comply to the system or its requests, with B-change the goal is to cause a more enduring change in behavior than a simple temporal compliance. With A-change the goal is to influence the user's attitudes in addition to the behaviors, which can be an important factor behind sustainable and long-term B-change [57]. For further reading about behavior change in general and related techniques, we refer the reader to [62-63].

There are various ways in which digital wellness technologies (e.g., physical activity applications) can act as BCSSs. For example, by using digital wellness technologies, the users are exposed to different kinds of user experiences that can function as drivers for future behaviors [e.g., 16, 60-61]. Hence, digital wellness technologies can potentially change PA behaviors (e.g., amount of conducted PA) of its users, but as argued, further research is needed. The focus in the present follow-up study is on the behavior change (B-change).

\section{Methodology}

This study investigated does the use of a physical activity application promote PA levels among aged people. This was done by examining the changes in PA levels between three different time points: before taking the physical activity application into use, after four months of use, and after 12 months of use.

In summer 2019, the first wave of field groups in the research program took the application into use. These groups consisted a total of 142 participants. The next wave of field groups commenced in autumn 2019 and the third wave during the year 2020. This study focuses on the first wave of the field groups. The study was conducted in Finland, and all the field groups were recruited through the Finnish pensioners' associations. Each group was assigned a field researcher who assisted the participants in taking the application into use and gave guidance on using the application and its features. The participants used the application in their everyday life and also conducted PA according to their own preferences. In other words, they were not provided with any specific PA programs to follow or specific goals to reach out for, but instead could freely conduct PA how and when they wanted. The application as well as its use were free of charge for the participants, but they were required to have their own smartphone.

\subsection{The used application}

The physical activity application used in the study was designed and developed for the target group in the ongoing research program. It is an application operating on the Wellmo application platform [38], which supports Android and iOS operating systems and in which the application features constitute their own entity. The application is aimed to support the formation of PA and wellness routines in everyday life and is designed specifically for the aged people. The central features of the application are related to tracking PA. The application includes, for example, features for tracking and following conducted PA, as well as weekly, monthly, and yearly reports about the conducted PA. There is also a possibility to import data 
from external wellness services that are supported by the Wellmo application platform, such as Apple Health, Google Fit, Polar Flow, and Fitbit. The application is under constant development, and new versions with additional features to support PA routines are scheduled to be launched twice a year.

\subsection{Data collection}

This study followed a quantitative approach. The focus was on the first 12 months of use. The PA levels were measured before taking the application into use, after four months of use, and after 12 months of use. This was done to determine whether the possible changes in PA would occur already during the first months of use or take a longer time to actualize, and also in order to mitigate the influence of seasonal variation. The self-reported PA levels were collected with surveys and measured by using the IPAQ-E [9].

The IPAQ-E is a modified version of the shortformat IPAQ [39] validated with Swedish adults [40], and it has been culturally adapted and validated for the elderly [9]. The IPAQ and IPAQ-E are designed to provide a set of well-developed instruments that can be used internationally to obtain comparable estimates of PA levels [41]. The IPAQ is the most widely used and validated PA questionnaire [42-43] and thus well suited for the purpose of this study. The IPAQ-E focuses on collecting self-reported PA data regarding the time spent in sitting, in walking, in moderate PA, and in vigorous PA from a period of the past seven days. For this study, the IPAQ-E questionnaire was translated from Swedish to Finnish following the wording of the Finnish version of the short-format IPAQ. The study participants included Finnish and Swedish speakers as both are official languages in Finland, and thus, both language versions were used. The questionnaires are available from the authors by request.

As mentioned, the data for this study were collected from the first wave of field groups. The first round of data collection was conducted in summer 2019, the second in autumn 2019, and the third in summer 2020. The first and the second data collection were conducted with printed IPAQ-E questionnaires during field meetings that were organized with each field group separately. Before answering the questionnaires, the participants were given oral and written instructions on answering. There was no time limit for answering, and the participants could ask clarifications if they felt the need. The third data collection was conducted using an online questionnaire, and each participant received a survey invitation link to their emails. All participants gave a written informed consent. The local ethical committee was contacted before the start of the research program deeming that no separate approval was needed for this study.

\subsection{Data analysis}

The collected data were analyzed with the IBM SPSS Statistics 24 software. For the analysis, the Guidelines for the data processing and analysis of the International Physical Activity Questionnaire [44] and the guidelines for IPAQ-E use presented in [9] were followed.

First, before the analysis, the standard methods for the cleaning and treatment of IPAQ datasets were conducted as advised in [44 p. 10-11]. For example, in accordance with the truncation of data rules, if the reported times for walking, moderate, or vigorous activities exceeded $180 \mathrm{~min} /$ day, data were truncated to be equal to $180 \mathrm{~min} /$ day $[9,44]$.

Second, as advised in [9 p. 1853], the PA data (continuous variable) are presented in time in minutes spent in different intensities instead of converting into metabolic equivalent of task values (MET) and METminutes; and following the guidelines by [44], the PA data are presented in median minutes/week rather than means, together with the interquartile ranges.

Third, in addition to analyzing the PA levels, the participants were categorized into three PA categories: Low, Moderate, and High (categorical variable) based on the reported time of each activity in combination with a weighting factor for the different activities (i.e., a factor 3.3 for walking, 4.0 for moderate PA, and 8.0 for vigorous PA); for further details, see [9].

The changes in PA were analyzed by comparing the PA levels and PA categories before taking the application into use to those after four months of use and to those after 12 months of use. More specifically, the statistical significance of the changes in the PA levels (continuous variable) were analyzed with the Wilcoxon signed-rank test [45] as the focus was on medians rather than means. In turn, the statistical significance of the changes in the PA categories (categorical variable) were analyzed with the McNemar-Bowker test [46]. The threshold of statistical significance was set to $\mathrm{p}<.05$ for both the tests. However, because multiple comparisons were conducted (more specifically two comparisons - before vs. after 4 months and before vs. after 12 months) this threshold was adjusted with the Bonferroni correction [47], thus resulting in $p<.025(.05 / 2)$ to be used as the adjusted threshold of statistical significance. The potentially missing values were handled by excluding the responses of a particular participant to a particular item if the participant had not responded to it in all three data collection rounds. Some participants either missed the first or the second follow-up or 
discontinued their use of the application and dropped out from the research program. Hence, the exact number of respondents (n) slightly varies between the items.

\section{Results}

In total, there were 142 participants in the first wave of field groups. Of them, 98 responded to the IPAQ-E in all three data collection rounds. Of these 98 respondents, $34.4 \%$ were male and $65.6 \%$ female. The average age of the respondents was 69.4 years (standard deviation 4.2 years). Descriptive statistics of those 98 participants are reported in Table 1 .

\section{Table 1. Descriptives of the respondents}

\begin{tabular}{|l|c|c|}
\hline & $\mathbf{n}$ & $\mathbf{\%}$ \\
\hline Gender & & \\
\hline Male & 35 & 35.7 \\
\hline Female & 63 & 64.3 \\
\hline Other & 0 & 0 \\
\hline Age & & \\
\hline Under 60 years & 2 & 2.0 \\
\hline 60-64 years & 10 & 10.2 \\
\hline 65-69 years & 38 & 38.8 \\
\hline $70-74$ years & 36 & 36.7 \\
\hline 75 years or over & 12 & 12.2 \\
\hline Language & & \\
\hline Finnish & 62 & 63.3 \\
\hline Swedish & 36 & 36.7 \\
\hline Highest level of education & & \\
\hline Primary education & 2 & 2.1 \\
\hline Vocational qualifications & 12 & 12.4 \\
\hline Vocational education & 52 & 53.6 \\
\hline University of applied sciences & 7 & 7.2 \\
\hline University & 22 & 22.7 \\
\hline Other & 2 & 2.1 \\
\hline N/A & 1 & - \\
\hline
\end{tabular}

\subsection{Physical activity levels}

Following [9] and the guidelines by [44], the PA data are reported in median minutes/week spent in different intensities, together with the interquartile ranges. The results are reported in two tables: Table 2 presents the changes after four months of use, and Table 3 presents the changes after 12 months of use, along with the statistical significance of the changes from the Wilcoxon signed-rank test.
Table 2. Changes in time spent in different intensities after 4 months

\begin{tabular}{|l|c|c|c|c|c|c|}
\hline & & \multicolumn{2}{|c|}{ Before } & \multicolumn{2}{c|}{ After 4mo } & p \\
\hline & n & MED & $\begin{array}{c}\mathbf{2 5 - 7 5} \\
\text { PCTL }\end{array}$ & MED & $\begin{array}{c}\mathbf{2 5 - 7 5} \\
\text { PCTL }\end{array}$ & \\
\hline Sit & 77 & 2100 & $\begin{array}{c}1400- \\
2520\end{array}$ & 2100 & $\begin{array}{c}1680- \\
2842\end{array}$ & .232 \\
& & & $304-$ & 630 & $420-$ & .168 \\
Walk & 80 & 600 & 900 & & 910 & \\
\hline Mod & 82 & 300 & $180-$ & 270 & $180-$ & .313 \\
PA & & & 540 & & 460 & \\
\hline Vig & 85 & 80 & $0-$ & 120 & $8-$ & .795 \\
PA & & & 355 & & 240 & \\
\hline Sit = Sitting; Walk = Walking; Mod = Moderate; Vig = Vigorous; \\
MED = Median; 25-75 PCTL = 25th-75th percentile & \\
\hline
\end{tabular}

Regarding the changes in the median minutes per week spent in different intensities after four months of use, there was a small decrease in moderate PA, but an increase in walking and vigorous PA. The median minutes per week for sitting remained unchanged. None of the observed changes were statistically significant.

\section{Table 3. Changes in time spent in different} intensities after 12 months

\begin{tabular}{|c|c|c|c|c|c|c|}
\hline & & \multicolumn{2}{|c|}{ Before } & \multicolumn{2}{|c|}{ After $12 \mathrm{mo}$} & $\mathbf{p}$ \\
\hline & $\mathbf{n}$ & MED & $\begin{array}{l}25-75 \\
\text { PCTL }\end{array}$ & MED & $\begin{array}{l}25-75 \\
\text { PCTL }\end{array}$ & \\
\hline Sit & 77 & 2100 & $\begin{array}{c}1400- \\
2520\end{array}$ & 2100 & $\begin{array}{c}1470- \\
2538\end{array}$ & .577 \\
\hline Walk & 80 & 600 & $\begin{array}{c}304- \\
900\end{array}$ & 923 & $\begin{array}{l}420- \\
1260\end{array}$ & .001 \\
\hline $\begin{array}{l}\text { Mod } \\
\text { PA }\end{array}$ & 82 & 300 & $\begin{array}{c}180- \\
540\end{array}$ & 240 & $\begin{array}{c}120- \\
458\end{array}$ & .506 \\
\hline $\begin{array}{l}\text { Vig } \\
\text { PA }\end{array}$ & 85 & 80 & $\begin{array}{c}0- \\
355\end{array}$ & 100 & $\begin{array}{l}13- \\
315\end{array}$ & .968 \\
\hline $\begin{array}{l}\text { Sit }= \\
\text { MED }\end{array}$ & & $=\mathrm{W}$ & ; Mc & oder & $\begin{array}{l}\text { ig }=V \\
\text { le }\end{array}$ & rous; \\
\hline
\end{tabular}

Regarding the changes in the median minutes per week spent in different intensities after 12 months of use, there was a notable and a statistically significant increase in walking. In addition, there was a small decrease in moderate PA and a small increase in vigorous PA. However, these two latter changes were statistically not significant. The median minutes per week for sitting remained unchanged.

\subsection{Physical activity categories}

The changes in the PA category were examined by investigating the changes in the number of participants in the three different PA categories Low, Moderate, and High (based on the IPAQ-E PA categorization) [9] 
after four and 12 months of use (Table 4). More precisely, it was examined how many were increasingly active (i.e., moved from Low $\rightarrow$ Moderate/High or Moderate $\rightarrow$ High), decreasingly active (i.e., moved from High $\rightarrow$ Moderate/Low or Moderate $\rightarrow$ Low), or equally active (i.e., stayed in the same category) after four months of use (Table 5) and after 12 months of use (Table 6) in comparison to the initial state before taking the application into use. There were nine participants whose PA category could not be defined for all the three different time points due to missing responses in some of the IPAQ questions. Thus, the analyses concerning PA categories contained 88 participants.

\section{Table 4. Participants in the different PA categories $(n=88)$}

\begin{tabular}{|c|c|c|c|}
\hline & Before & After 4mo & After 12mo \\
\hline PA category & $\mathbf{\%}$ & $\mathbf{\%}$ & $\mathbf{\%}$ \\
\hline Low & 8.0 & 3.4 & 1.1 \\
\hline Moderate & 25.0 & 25.0 & 14.8 \\
\hline High & 67.0 & 71.6 & 84.1 \\
\hline
\end{tabular}

Table 5. Changes in the PA categories after 4 months $(n=88)$

\begin{tabular}{|l|c|c|c|}
\hline PA category & $\begin{array}{c}\text { After 4mo } \\
\text { Low }\end{array}$ & $\begin{array}{c}\text { After 4mo } \\
\text { Moderate }\end{array}$ & $\begin{array}{c}\text { After 4mo } \\
\text { High }\end{array}$ \\
\hline Before Low & 0 & 2 & 5 \\
\hline Before Moderate & 0 & 10 & 12 \\
\hline Before High & 3 & 10 & 46 \\
\hline
\end{tabular}

After four months of use, $21.6 \%$ of the participants were increasingly active, $14.8 \%$ were decreasingly active, and $63.6 \%$ were equally active. All seven participants who were initially in the Low category, shifted up to Moderate or High category. Moreover, 12 out of the 22 participants who were initially in the Moderate category shifted up to High category. In contrast, 13 participants, all of whom were initially in the High category, shifted down to a lower PA category. However, the McNemar-Bowker test suggested that the overall changes (increase or decrease) in PA was statistically not significant $\left(\chi^{2}(3)\right.$ $=2.682, \mathrm{p}=.443$ ).
Table 6. Changes in the PA categories after 12 months $(n=88)$

\begin{tabular}{|l|c|c|c|}
\hline PA category & $\begin{array}{c}\text { After 12mo } \\
\text { Low }\end{array}$ & $\begin{array}{c}\text { After 12mo } \\
\text { Moderate }\end{array}$ & $\begin{array}{c}\text { After 12mo } \\
\text { High }\end{array}$ \\
\hline Before Low & 0 & 0 & 7 \\
\hline Before Moderate & 1 & 6 & 15 \\
\hline Before High & 0 & 7 & 52 \\
\hline
\end{tabular}

After 12 months of use, $25.0 \%$ of the participants were increasingly active, $9.1 \%$ were decreasingly active, and $65.9 \%$ were equally active. The equally active participants could belong to any of the three PA categories. Interestingly, all of the seven participants who were initially in the Low category as well as 15 out of the 22 participants who were initially in the Moderate category, had now increased their PA to reach High PA category. In contrast, eight participants had shifted to a lower PA category. The McNemarBowker test also suggested that the overall changes (increase or decrease) in PA was statistically significant $\left(\chi^{2}(3)=10.909, p=.012\right)$.

\section{Discussion and conclusions}

The main purpose of this study was to investigate the following research question: Does the use of a physical activity application promote physical activity levels among aged people? The study participants took into use a physical activity application that allowed them to track and follow their everyday PA. The selfreported PA was measured by using the International Physical Activity Questionnaire modified for the elderly (IPAQ-E) [9] at three different time points: before taking the application into use, after four months of use, and after 12 months of use.

Regarding the PA levels, the changes in four types of PA (sitting, walking, moderate activity, and vigorous activity) were measured. In general, the results show rather modest changes in the PA levels after the first four and 12 months of use. There was a small but statistically not significant decrease in moderate PA and an increase in vigorous PA at both after four months and after 12 months of use in comparison to the initial level. Regarding walking, there was a notable and a statistically significant increase after 12 months of use, which was not observable after four months of use.

There was no change in the sitting times at neither after four nor after 12 months of use. One likely reason for this is that the application did not include features for tracking sitting time. This suggests that a physical activity application without a designated feature for tracking sitting is not an effective solution for reducing 
sitting times. This is something for the practitioners to consider when designing applications aimed to promote healthy PA behaviors, as too much sitting has been shown to have detrimental health effects [e.g., 48].

To summarize the results concerning the PA levels, although there was a statistically significant change only in the increased walking after 12 months of use, in general, a modest but positive change could be seen in the PA levels of the participating aged people. Further, the changes were more substantial after 12 months of use than after four months of use. These findings are mostly in line with the findings of a recent systematic review on the ability of physical activity monitors to promote PA behaviors among older adults [7].

In addition to measuring the PA levels, the participants were categorized into three PA categories based on their overall PA. These categories, as detailed in [9], were Low, Moderate, and High. Further, the shifts of individual participants from one category to another were investigated. Overall, while most participants remained equally active in terms of the PA category, there were more increasingly active than decreasingly active participants. The overall change (increase or decrease) was statistically significant after 12 months, but not after four months of use.

More specifically, especially a shift from the Low and Moderate PA categories to the High PA category could be observed at both after four months and after 12 months of use. However, there was a shift to the other direction as well, as some participants shifted to a lower PA category. Of them, all but one were initially in the High category. The reasons for shifting to a lower PA category were not investigated in this study, but such a shift could potentially happen due to any incidents or other changes in the life of an individual, such as an injury or sickness, hindering the possibility to maintain PA levels. Relating to this, it should be noted that the participants seemed to represent a rather physically active share of the aged population as twothirds belonged to the High(est) PA category already before taking the application into use. Hence, in their case, a potential shift could only occur to a lower category.

To conclude, by examining the mere median minutes in different types of PA per week, it would seem that the overall (positive) change in PA behavior was modest. However, when examining the PA categories, it can be seen that a participant rather shifted to a higher PA category than to a lower PA category. Especially those initially in the low category increased their PA to reach a higher category. This supports the findings of [49], who found that among older adults, wearable PA tracker use provides the greatest benefits to the physically less-active individuals and former non-users of such technology.

When examining these findings from the scope of behavior change and BCSSs, it seems that physical activity applications can act as BCSSs and support change in PA behaviors. This change can also be longterm, as suggested by the findings concerning PA after 12 months of use. Whether physical activity applications can also support attitude change [57] towards PA, was outside the scope of this study.

Overall, the present study suggests that physical activity applications used in everyday life have potential in promoting PA behaviors among aged people, especially among those with lower PA levels.

\section{Limitations and future research}

This study has some limitations that should be acknowledged. First, the timing of the data collection may have some influence on the results: the first PA data from the period of the past seven days was collected in summer, whereas the first follow-up after four months was collected in autumn. The second follow-up after 12 months was again in summer. Notably, the time of the year may influence the PA levels of an individual in various ways. Second, as the participants were not necessarily tracking PA before taking the application into use, they could have had a less accurate view on their initial PA level, whereas by using the application, a participant could have become more aware of his/her PA level. Thus, the latter two measurements of PA might have been more accurate. Third, on average, the participants represented a rather physically active share of the aged population, which places its limits to the findings. For future research, it would be beneficial to get more participants especially from the lower PA categories to minimize nonparticipation bias. Fourth, as there was no control group in the study, it is not certain whether the changes in PA behaviors were mainly because of using the application or because of taking part in the study. It is also possible that the change in PA has been influenced by some other uncontrolled factor, such as the COVID19 pandemic, which in Finland resulted in social distancing rules for the aged people and temporary closing of certain sporting facilities between the first and second follow-ups. This has potentially influenced the PA behaviors of aged people [50-53] and subsequently the participants' PA levels around the second follow-up.

Future research could also study the use of physical activity applications and their potential to support PA behavior change in different countries or with different target groups. Additionally, it would also be interesting 
to conduct similar research with other types of digital wellness technologies and also focus on attitude changes. As long-term research on related topics are much called for, the authors plan to conduct further follow-up studies with a longer use period and more participants in the research program that has already produced earlier short-term study findings [e.g., 5456]. Indeed, more research on this topic is warranted.

\section{References}

[1] United Nations. World population ageing 2019, 2019, https:/www.un.org/en/development/desa/population/publicat ions/pdf/ageing/WorldPopulationAgeing2019-Highlights.pdf, last accessed 1.6.2020.

[2] Eurostat. Population structure and ageing, 2019, https://ec.europa.eu/eurostat/statistics-

explained/index.php/Population_structure_and_ageing, last accessed 1.6.2020.

[3] World Health Organization. Physical activity, 2018, https://www.who.int/news-room/fact-sheets/detail/physicalactivity/, last accessed 1.6.2020.

[4] Hoogendijk, E.O., Afilalo, J., Ensrud, K.E., Kowal, P., Onder, G., and Fried, L.P. "Frailty: implications for clinical practice and public health", The Lancet, 394, pp. 1365-1375, 2019.

[5] Jonasson, L. Aerobic fitness and healthy brain aging: cognition, brain structure, and dopamine, Umeå University, Sweden, 2017.

[6] Allmér, H. Servicescape for digital wellness services for young elderly, Åbo Akademi University Press, Turku, Finland, 2018.

[7] Larsen, R.T., Christensen, J., Juhl, C.B., Andersen, H.B., and Langberg, H. "Physical activity monitors to enhance amount of physical activity in older adults - a systematic review and meta-analysis", European Review of Aging and Physical Activity, 16, 7, 2019.

[8] Seifert, A., Schlomann, A., Rietz, C., Schelling, H.R. "The use of mobile devices for physical activity tracking in older adults' everyday life", Digital Health, 3, pp. 1-12, 2017.

[9] Hurtig-Wennlöf, A., Hagströmer, M., and Olsson, L.A. "The International Physical Activity Questionnaire modified for the elderly: aspects of validity and feasibility", Public Health Nutrition, 13, pp. 1847-1854, 2010.

[10] Kettunen, E., Kari, T., Moilanen, P., Vehmas, H., and Frank, L. "Ideal types of sport and wellness technology users", In Proceedings of the 11th Mediterranean Conference on Information Systems, 12 pages. AIS, Genoa, Italy, 2017.
[11] Moilanen, P., Salo, M., and Frank, L. "Inhibitors, enablers and social side winds: explaining the use of exercise tracking systems", In Proceedings of the 27th Bled eConference, pp. 23-37. University of Maribor Press, Bled, Slovenia, 2014.

[12] Carlsson, C., and Walden, P. "Digital coaching to build sustainable wellness routines for young elderly", In Proceedings of the 30th Bled eConference "Digital Transformation - From Connecting Things to Transforming Our Lives", pp. 57-70. University of Maribor, Bled, Slovenia, 2017.

[13] de Vries, H.J., Kooiman, T.J., van Ittersum, M.W., van Brussel, M., and de Groot, M. "Do activity monitors increase physical activity in adults with overweight or obesity? A systematic review and meta-analysis", Obesity, 24, pp. 20782091, 2016.

[14] Romeo, A., Edney, S., Plotnikoff, R., Curtis, R., Ryan, J., Sanders, I., ... Maher, C. "Can smartphone apps increase physical activity? systematic review and meta-analysis", Journal of Medical Internet Research, 21, e12053, 2019.

[15] Stephenson, A., McDonough, S.M., Murphy, M.H., Nugent, C.D., and Mair, J.L. "Using computer, mobile and wearable technology enhanced interventions to reduce sedentary behaviour: a systematic review and meta-analysis", Journal of Behavioral Nutrition and Physical Activity, 14, $105,2017$.

[16] Kari, T., and Rinne, P. 'Influence of digital coaching on physical activity: motivation and behaviour of physically inactive individuals", In Proceedings of the 31st Bled eConference "Digital Transformation - Meeting the Challenges", pp. 127-145. University of Maribor Press, Bled, Slovenia, 2018.

[17] Kettunen, E., and Kari, T. "Can sport and wellness technology be my personal trainer? teenagers and digital coaching", In Proceedings of the 31st Bled eConference "Digital Transformation - Meeting the Challenges", pp. 463476. University of Maribor press, Bled, Slovenia, 2018.

[18] Sell, A., Walden, P., Carlsson, C., Helmefalk, M., and Marcusson, L. "Digital Coaching to Support University Students' Physical Activity", In Proceedings of the 32nd Bled eConference "Humanizing Technology for a Sustainable Society", pp. 599-618. University of Maribor Press, Bled, Slovenia, 2019.

[19] Gordon, M., Althoff, T., and Leskovec, J. "Goal-setting and achievement in activity tracking apps: a case study of MyFitnessPal", In Proceedings of the World Wide Web Conference, pp. 571-582. ACM, New York, NY, 2019.

[20] Kirwan, M., Duncan, M., and Vandelanotte, C. "Smartphone apps for physical activity: a systematic review", Journal of Science and Medicine in Sport, 16, e47, 2013. 
[21] Sullivan, A.N., and Lachman, M.E. "Behavior change with fitness technology in sedentary adults: a review of the evidence for increasing physical activity", Frontiers in Public Health, 4, 289, 2017.

[22] Kari, T., Piippo, J., Frank, L., Makkonen, M., and Moilanen, P. "To gamify or not to gamify? gamification in exercise applications and its role in impacting exercise motivation", In Proceedings of the 29th Bled eConference "Digital economy", pp. 393-405. University of Maribor, Bled, Slovenia, 2016.

[23] Koivisto, J., and Hamari, J. "The rise of motivational information systems: a review of gamification research", International Journal of Information Management, 45, pp. 191-210, 2019.

[24] Kari, T. "Can exergaming promote physical fitness and physical activity? a systematic review of systematic reviews", International Journal of Gaming and ComputerMediated Simulations, 6, pp. 59-77, 2014.

[25] Kari, T., Salo, M., and Frank, L. "Role of Situational Context in Use Continuance After Critical Exergaming Incidents", Information Systems Journal, 30, pp. 596-633, 2020.

[26] Loos, E., and Zonneveld, A. "Silver gaming: serious fun for seniors?", In International Conference on Human Aspects of IT for the Aged Population, pp. 330-341. Springer, Cham, 2016.

[27] Mueller, F., Khot, R.A., Gerling, K., and Mandryk, R. "Exertion games", Foundations and Trends ${ }^{\circledR}$ in HumanComputer Interaction, 10, pp. 1-86, 2016.

[28] Kang, M., Marshall, S.J., Barreira, T.V., and Lee, J.O. "Effect of pedometer-based physical activity interventions: a meta-analysis", Research Quarterly for Exercise and Sport, 80, pp. 648-655, 2009.

[29] Kari, T., Kettunen, E., Moilanen, P., and Frank, L. "Wellness technology use in everyday life: a diary study", In: Proceedings of the 30th Bled eConference "Digital Transformation - From Connecting Things to Transforming Our Lives", pp. 279-294. University of Maribor, Bled, Slovenia, 2017.

[30] Wang, J.B., Cataldo, J.K., Ayala, G.X., Natarajan, L., Cadmus-Bertram, L.A., ... Pierce, J.P. "Mobile and wearable device features that matter in promoting physical activity", Journal of Mobile Technology in Medicine, 5, pp. 2-11, 2016.

[31] Miyamoto, S.W., Henderson, S., Young, H.M., Pande, A., and Han, J.J. "Tracking health data is not enough: a qualitative exploration of the role of healthcare partnerships and mhealth technology to promote physical activity and to sustain behavior change", JMIR mHealth and uHealth, 4, e5, 2016.
[32] Attig, C., and Franke, T. "Abandonment of personal quantification: a review and empirical study investigating reasons for wearable activity tracking attrition", Computers in Human Behavior, 102, pp. 223-237, 2020.

[33] Warraich, M.U. "Wellness routines with wearable activity trackers: a systematic review", In Proceedings of the 10th Mediterranean Conference on Information Systems, 13 pages. AIS, Paphos, Cyprus, 2016.

[34] Changizi, M., and Kaveh, M.H. "Effectiveness of the mHealth technology in improvement of healthy behaviors in an elderly population-A systematic review", mHealth, 3, $51,2017$.

[35] Muellmann, S., Forberger, S., Möllers, T., Bröring, E., Zeeb, H., and Pischke, C. R. "Effectiveness of eHealth interventions for the promotion of physical activity in older adults: A systematic review", Preventive Medicine, 108, pp. 93-110, 2018

[36] Yerrakalva, D., Yerrakalva, D., Hajna, S., and Griffin, S. "Effects of mobile health app interventions on sedentary time, physical activity, and fitness in older adults: Systematic review and meta-analysis", Journal of Medical Internet Research, 21, e14343, 2019.

[37] Stockwell, S., Schofield, P., Fisher, A., Firth, J., Jackson, S.E., Stubbs, B., and Smith, L. "Digital behavior change interventions to promote physical activity and/or reduce sedentary behavior in older adults: A systematic review and meta-analysis", Experimental Gerontology, 120, pp. 68-87, 2019.

[38] Wellmo. Mobile health platform, 2019, https://www.wellmo.com/platform/, last accessed 1.6.2020.

[39] Craig, C.L., Marshall, A.L., Sjöström, M., Bauman, A. E., Booth, M.L., Ainsworth, B.E., ... Oja, P. "International physical activity questionnaire: 12-country reliability and validity", Medicine \& Science in Sports \& Exercise, 35, pp. 1381-1395, 2003

[40] Ekelund, U., Sepp, H., Brage, S., Becker, W., Jakes, R., Hennings, M., and Wareham, N.J. "Criterion-related validity of the last 7-day, short form of the International Physical Activity Questionnaire in Swedish adults", Public Health Nutrition, 9, pp. 258-265, 2006.

[41] IPAQ group. International Physical Activity Questionnaire, 2005a, https://sites.google.com/site/ theipaq/home/, last accessed 5.6.2020.

[42] Lee, P.H., Macfarlane, D.J., Lam, T.H., and Stewart, S.M. "Validity of the international physical activity questionnaire short form (IPAQ-SF): A systematic review", International Journal of Behavioral Nutrition and Physical Activity, 8, 115, 2011.

[43] Van Poppel, M.N., Chinapaw, M.J., Mokkink, L.B., Van Mechelen, W., and Terwee, C.B. "Physical activity 
questionnaires for adults: a systematic review of measurement properties", Sports Medicine, 40, pp. 565-600, 2010.

[44] IPAQ group. Guidelines for Data Processing and Analysis of the International Physical Activity Questionnaire (IPAQ), 2005b, https://sites.google.com/site/theipaq/scoringprotocol/, last accessed 5.6.2020.

[45] Wilcoxon, F. "Individual Comparisons by Ranking Methods", Biometrics Bulleting, 1, pp. 80-83, 1945.

[46] Bowker, A.H. "A test for symmetry in contingency tables", Journal of the American Statistical Association, 43, pp. 572-574, 1948.

[47] Bonferroni, C. "Teoria statistica delle classi e calcolo delle probabilita", Pubblicazioni del R Istituto Superiore di Scienze Economiche e Commericiali di Firenze, 8, pp. 3-62, 1936.

[48] Dunstan, D.W., Howard, B., Healy, G.N. and Owen, N. "Too much sitting-a health hazard", Diabetes research and Clinical Practice, 97, pp. 368-376, 2012.

[49] Kononova, A., Li, L., Kamp, K., Bowen, M., Rikard, R.V., Cotten, S., and Peng, W. "The use of wearable activity trackers among older adults: Focus group study of tracker perceptions, motivators, and barriers in the maintenance stage of behavior change", JMIR mHealth and uHealth, 7, e9832, 2019.

[50] Aubertin-Leheudre, M., and Rolland. Y. "The importance of physical activity to care for frail older adults during the COVID-19 pandemic", Journal of the American Medical Directors Association, published ahead of print, 2020.

[51] Said, C.M., Batchelor, F., and Duque, G. "Physical activity and exercise for older people during and after the COVID-19 pandemic: A path to recovery", Journal of the American Medical Directors Association, published ahead of print, 2020.

[52] Sepúlveda-Loyola, W., Rodríguez-Sánchez, I., PérezRodríguez, P., Ganz, F., Torralba, R., Oliveira, D.V., and Rodríguez-Mañas, L. "Impact of social isolation due to COVID-19 on health in older people: Mental and physical effects and recommendations", Journal of Nutrition, Health \& Aging, published ahead of print, 2020.

[53] Hall, G., Laddu, D.R., Phillips, S.A., Lavie, C.J., and Arena, R. "A tale of two pandemics: How will COVID-19 and global trends in physical inactivity and sedentary behavior affect one another?", Progress in Cardiovascular Diseases, published ahead of print, 2020.

[54] Kari, T., Makkonen, M., Frank, L., Carlsson, J., and Sell, A. "The Effects of Using a Mobile Wellness
Application on Physical Activity Levels: A Four-Month Follow-Up Study Among Aged People", In Proceedings of the 33rd Bled eConference "Enabling Technology for a Sustainable Society", pp. 455-468. University of Maribor Press. Bled, Slovenia, 2020.

[55] Makkonen, M., Kari, T., and Frank, L. "Applying UTAUT2 to Explain the Use of Physical Activity Logger Applications Among Young Elderly", In Proceedings of the 33rd Bled eConference "Enabling Technology for a Sustainable Society", pp. 567-582. University of Maribor Press. Bled, Slovenia, 2020.

[56] Carlsson, C., Kari, T., Makkonen, M., Frank, L., and Walden, P. "Sustainable Physical Activity Programs for Young Elderly - A Fuzzy AHP Approach", In Proceedings of the 33rd Bled eConference "Enabling Technology for a Sustainable Society", pp. 423-438. University of Maribor Press. Bled, Slovenia, 2020.

[57] Oinas-Kukkonen, H. "A foundation for the study of behavior change support systems", Personal and Ubiquitous Computing, 17, pp. 1223-1235, 2013.

[58] Fogg, B.J. Persuasive technology: using computers to change what we think and do, Morgan Kaufmann Publishers, San Francisco, 2003.

[59] Oduor, M., and Oinas-Kukkonen, H. "Committing to change: a persuasive systems design analysis of user commitments for a behaviour change support system", Behaviour \& Information Technology, published ahead of print, pp. 1-19, 2019.

[60] Karppinen, P., Oinas-Kukkonen, H., Alahäivälä, T., Jokelainen, T., Keränen, A. M., Salonurmi, T., and Savolainen, M. "Persuasive user experiences of a health Behavior Change Support System: A 12-month study for prevention of metabolic syndrome", International Journal of Medical Informatics, 96, pp. 51-61, 2016.

[61] Kari, T., Koivunen, S., Frank, L., Makkonen, M., and Moilanen, P. "Critical Experiences During the Implementation of a Self-tracking Technology", In Proceedings of the 20th Pacific Asia Conference on Information Systems, pp. 1-16. AIS. Chiayi, Taiwan, 2016.

[62] Michie, S., and Johnston, M. "Theories and techniques of behaviour change: Developing a cumulative science of behaviour change", Health Psychology Review, 6, pp. 1-6, 2012.

[63] Davis, R., Campbell, R., Hildon, Z., Hobbs, L., and Michie, S. "Theories of behaviour and behaviour change across the social and behavioural sciences: a scoping review”, Health Psychology Review, 9, pp. 323-344, 2015. 